\title{
EFFECT OF ACETIC ACID ON POLLUTANT DECOMPOSITION IN TEXTILE WASTEWATER TREATED BY THE FENTON METHOD
}

\begin{abstract}
The aim of the study was to determine the effect of acetic acid on pollutant decomposition in textile wastewater subjected to the Fenton process. To clearly assess the effect of acetic acid on treatment efficiency for subsequent types of textile wastewater, COD reduction was calculated for mixtures of a given wastewater type with acetic acid. The calculated COD values were compared to COD obtained in experiments with the oxidation of wastewater-acetic acid mixtures in the Fenton process. The presence of acetic acid seriously deteriorated conditions of wastewater treatment which affected the efficiency of treatment processes.
\end{abstract}

\section{INTRODUCTION}

Among the methods which enable decreasing of pollutant concentrations in wastewaters, one of the simplest and cheapest is Fenton's reaction. It consists in nonselective and highly efficient oxidation of organic compounds by means of hydroxyl radicals [1-3]. They are formed in a chain process of decomposition of hydrogen peroxide in the presence of bivalent iron salts which is represented by the following reaction:

$$
\mathrm{H}_{2} \mathrm{O}_{2}+\mathrm{Fe}^{2+} \rightarrow \mathrm{Fe}^{3+}+\mathrm{OH}^{-}+\mathrm{HO}^{\cdot}
$$

The process is a radical reaction during which significant quantities of hydroxyl radicals $\mathrm{HO}^{*}$ capable of oxidation of even the most resistant pollutants are generated. Basic advantages of this method include high efficiency of the oxidation reaction, inexpensive and easily available substrates and a simple procedure.

\footnotetext{
*Textile Research Institute, ul. Brzezińska 5/15, 92-103 Łódź, Poland; e-mail: 1kos@iw.lodz.pl

**Technical University of Łódź, Institute of Applied Radiation Chemistry, ul. Wróblewskiego 15, 93-590 Łódź, Poland; e-mail: japerepi@mitr.p.lodz.pl
} 
In our previous studies we examined decomposition of impurities present in textile wastewater treated by the Fenton method [4]. In this paper, we present results of our researches on pollutant decomposition in textile wastewater in the presence of acetic acid.

Among low-molecular compounds which may affect the oxidation processes and their efficiency in the case of textile wastewater acetic acid is of particular importance. This is a compound occurring very often in the textile wastewater because of its general use in cotton fibre dyeing. On the other hand, when wastewater oxidation with the use of hydroxyl radicals generated among others in the Fenton process is applied, acetic acid can be formed as an intermediate or final product due to the oxidation of highmolecular compounds. Owing to the presence of acetic acid in the wastewater it can affect significantly the mechanisms of oxidation. Moreover, acetic acid can affect seriously the wastewater characteristics because of high COD values which it brings about. At the same time it is an undesirable compound which hampers biological treatment of wastewater.

Acetic acid is compound hardly degradable during oxidation. For instance, the reactivity of hydroxyl radicals towards acetic acid is equal to only 0.275 of hydroxyl radical reactivity towards acetone [5]. On the other hand, acetic acid is practically degraded completely to $\mathrm{CO}_{2}$ and no such products of decomposition are formed as methanol, formaldehyde, or formic acid.

Mizuno et al. [6] studied the products of pollutant oxidation in the wastewater formed under the influence of hydroxyl radicals generated in the oxidation process with the use of ozone and hydrogen peroxide. They found that as a result of oxidation total organic carbon concentration in the wastewater was decreased distinctly and they observed an increase of carboxylic acids: formic, acetic and oxalic acids. In the oxidized wastewater, the content of total organic carbon generated from carboxylic acids reached $50 \%$ of the total content of TOC. Additionally, it was found that during the oxidation process organic compounds present in the wastewater were fully mineralized to $\mathrm{CO}_{2}$ in $70 \%$, and in $30 \%$ they were transformed into carboxylic acids.

When studying the Fenton process in industrial wastewater containing acetic acid in the amount from 1 to $4 \mathrm{~mol} / \mathrm{dm}^{3}$, COD reduction reached 50\% [7]. The efficiency of acetic acid decomposition increased upon increasing concentration of ferrous ions and the oxidation processes were strongly exothermic.

Ma et al. [8] investigated the effect of low-molecular organic acids on pollutant degradation by means of the Fenton process. The effect of oxalic, malonic and ethylenediaminetetraacetic (EDTA) acids on the decomposition of Malachite Green (MG), 2,4,5-trichlorophenol (TCP) and 5,5-dimethyl-1-pyrroline-N-oxide (DMPO) was investigated. It was found that the degradation of Malachite Green was completely blocked in the presence of some low-molecular organic acids. The addition of hydroquinone launched oxidation of the dye particles. However, at the same time intermediate products of decomposition were formed which caused that the mineralization was 
practically none. Similar relations were observed in the case of oxidation of TCP and DMPO particles. Complete mineralization of pollutants was achieved when the decomposition processes were enhanced by the addition of hydroquinone combined with a simultaneous UV irradiation of samples.

Thus, low-molecular compounds present in the wastewater can affect appreciably the mechanism and efficiency of the Fenton process [9-12]. These phenomena are relatively little known although they can be very important for the assessment of technological applicability of the Fenton process to a given type of wastewater treatment. Hence, the aim of the study presented in this paper was to determine the effect of acetic acid on pollutant decomposition in textile wastewater subjected to the Fenton process.

\section{EXPERIMENTAL}

Textile wastewater of various concentrations and compositions has been examined, covering concentrated dyeing and washing wastewater, averaged general process wastewater and nanofiltration concentrate. The tested washing wastewater-1 came from the prewashing of cotton fabric with a polyester core. A non-ionic detergent was used for washing. The wastewater $\mathrm{pH}$ was 7.3 and $\mathrm{COD}=2190 \mathrm{mg} \mathrm{O} / \mathrm{dm}^{3}$. Washing wastewater-2 was generated during the prewashing of polyester knitwear. An anionic detergent was used for washing. $\mathrm{pH}$ of the wastewater was 7.2, $\mathrm{COD}=350 \mathrm{mg} \mathrm{O} / \mathrm{dm}^{3}$ and the content of anionic detergents was $30 \mathrm{mg} / \mathrm{dm}^{3}$. The tested dyeing wastewater was produced during the dyeing of cotton knitwear with reactive dyes. $\mathrm{pH}$ of the wastewater was $10.3, \mathrm{COD}=4170 \mathrm{mg} \mathrm{O} / \mathrm{dm}^{3}$ and the content of chlorides was $2100 \mathrm{mg} / \mathrm{dm}^{3}$. The general averaged process wastewater came from one of Łódź textile plants producing cotton fabrics. $\mathrm{pH}$ of the wastewater was $9.2, \mathrm{COD}=1720 \mathrm{mg} \mathrm{O} / \mathrm{dm}^{3}$ and the content of anionic detergents was $9.8 \mathrm{mg} / \mathrm{dm}^{3}$. The tested concentrate came from nanofiltration of the wastewater from cotton knitwear dyeing. $\mathrm{pH}$ of the concentrate was 10.3 and $\mathrm{COD}=4930 \mathrm{mg} \mathrm{O} 2 / \mathrm{dm}^{3}$.

Fenton's reagent used in the experiments consisted of about $30 \%$ hydrogen peroxide a.p. (PPH POCh, Gliwice) and iron(II) salt in the form of technical $\mathrm{FeSO}_{4} \cdot 7 \mathrm{H}_{2} \mathrm{O}$. 91.3\% acetic acid (POCh, Gliwice) was used.

In the experiments, acetic acid in the amount from 0.4 to $8.3 \mathrm{~g} / \mathrm{dm}^{3}$ was added to the wastewater prior to treatment. Next, the wastewater $\mathrm{pH}$ was corrected to 3 with solution of sulfuric acid at the concentration of $1 \mathrm{~mol} / \mathrm{dm}^{3}$. Then, oxidation was carried out by the Fenton method. To the solution a determined amount of solid ferric sulfate was added and mixed until complete dissolution. Next, hydrogen peroxide was added drop wise. The solution was agitated vigorously for $2 \mathrm{~min}$, then slowly for the next $10 \mathrm{~min}$, and finally left for $24 \mathrm{~h}$. After that time the solution was neutralized with $10 \% \mathrm{NaOH}$ to $\mathrm{pH}$ around 11 . After the next $24 \mathrm{~h}$, the solution was decanted and fil- 
tered. The sample was analyzed, COD, and in the case of certain wastewater types the content of anionic surfactants was determined.

\section{RESULTS AND DISCUSSION}

The effect of acetic acid on pollutant decomposition was studied in five types of textile wastewater with different initial COD ranging from 350 to $4930 \mathrm{mg} \mathrm{O}_{2} / \mathrm{dm}^{3}$.

In the case of washing wastewater-1 with initial COD $2190 \mathrm{mgO}_{2} / \mathrm{dm}^{3} 0.8,2.1$, $4.2,6.2$ and $8.3 \mathrm{~g} / \mathrm{dm}^{3}$ of acetic acid was added. The concentration of $\mathrm{FeSO}_{4} \cdot 7 \mathrm{H}_{2} \mathrm{O}$ was constant and equal to $2 \mathrm{~g} / \mathrm{dm}^{3}$. The dose of hydrogen peroxide was also constant and equal to $40 \mathrm{~cm}^{3} / \mathrm{dm}^{3}$. The values of COD of the wastewater before and after the Fenton process are shown in Fig. 1.

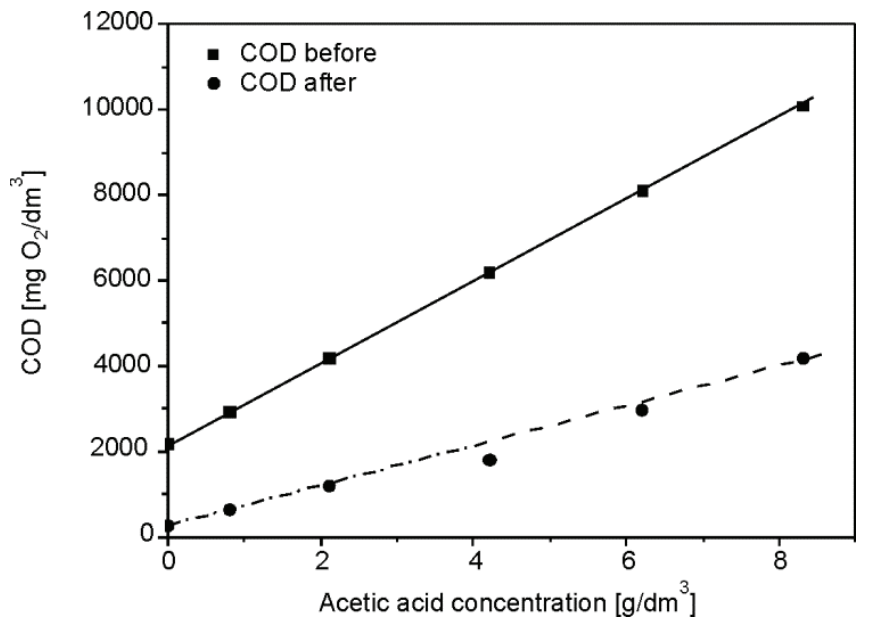

Fig. 1. Effect of acetic acid on COD of washing wastewater-1 before and after the Fenton process.

Amounts of $\mathrm{FeSO}_{4} \cdot 7 \mathrm{H}_{2} \mathrm{O}-2 \mathrm{~g} / \mathrm{dm}^{3}$, and $\mathrm{H}_{2} \mathrm{O}_{2}-40 \mathrm{~cm}^{3} / \mathrm{dm}^{3}$

Both initial COD of washing wastewater-1 and that obtained after the Fenton process changed linearly upon increasing concentration of acetic acid. However, the slopes of both straight lines were different which caused that the percentage of COD reduction decreased from $78 \%$ to $59 \%$ while the concentration of $\mathrm{CH}_{3} \mathrm{COOH}$ increased from 0.8 to $8.3 \mathrm{~g} / \mathrm{dm}^{3}$. The maximum COD reduction in washing wastewater-1 was $87 \%$ under the experimental conditions.

For washing wastewater-2 with initial COD of $350 \mathrm{mg} \mathrm{O} / \mathrm{dm}^{3}$, the applied doses of acetic acid were $0.4,0.8,2.1,4.2$ and $8.3 \mathrm{~cm}^{3} / \mathrm{dm}^{3}$. The doses of both ferric sulfate and hydrogen peroxide were lower amounting to $1.6 \mathrm{~g} / \mathrm{dm}^{3}$ and $20 \mathrm{~cm}^{3} / \mathrm{dm}^{3}$, respectively. The values of $\mathrm{COD}$ in the wastewater before and after the Fenton process are shown in Fig. 2. 


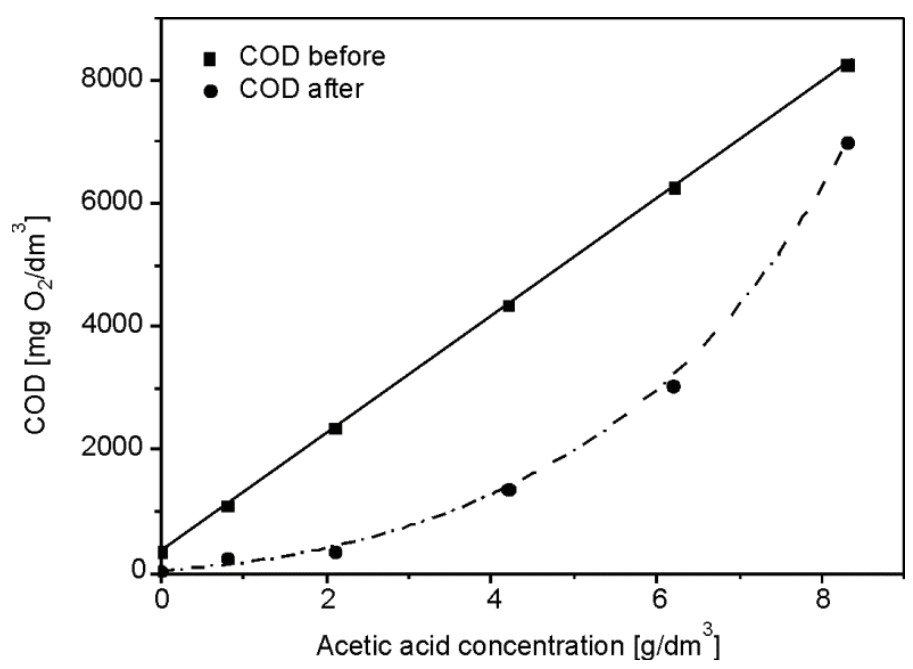

Fig. 2. Effect of acetic acid on COD of washing wastewater-2, before and after the Fenton process.

Amounts of $\mathrm{FeSO}_{4} \cdot 7 \mathrm{H}_{2} \mathrm{O}-1.6 \mathrm{~g} / \mathrm{dm}^{3}$, and $\mathrm{H}_{2} \mathrm{O}_{2}-20 \mathrm{~cm}^{3} / \mathrm{dm}^{3}$

As follows from the figure, upon increasing concentration of acetic acid in washing wastewater-2 after the initial growth an evident decrease of the Fenton process efficiency was reported. In the experimental conditions, the efficiency of treatment decreased from the maximum $85 \%$ to only $15 \%$.

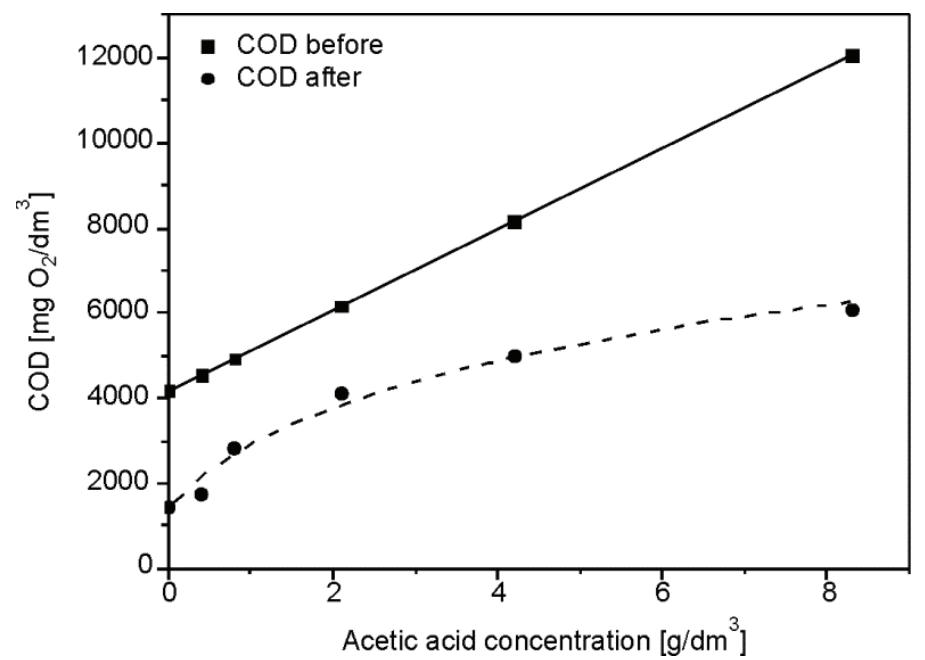

Fig. 3. Effect of acetic acid on COD in dyeing wastewater before and after the Fenton process.

Amounts of $\mathrm{FeSO}_{4} \cdot 7 \mathrm{H}_{2} \mathrm{O}-1.6 \mathrm{~g} / \mathrm{dm}^{3}$, and $\mathrm{H}_{2} \mathrm{O}_{2}-20 \mathrm{~cm}^{3} / \mathrm{dm}^{3}$ 
In the case of the dyeing wastewater with initial $\mathrm{COD}=4170 \mathrm{mg} \mathrm{O}_{2} / \mathrm{dm}^{3}$, the doses of acetic acid added were $0.4,0.8,2.1,4.2$ and $8.3 \mathrm{~cm}^{3} / \mathrm{dm}^{3}$. Constant doses of ferric sulfate and hydrogen peroxide being $1.6 \mathrm{~g} / \mathrm{dm}^{3}$ and $20 \mathrm{~cm}^{3} / \mathrm{dm}^{3}$, respectively, were added. Figure 3 shows the values of COD in the wastewater before and after the Fenton process.

In the dyeing wastewater, the Fenton process led to the $65.5 \%$ COD reduction. This value decreased with an increase of the concentration of $\mathrm{CH}_{3} \mathrm{COOH}$ to $32.7 \%$ (for $2.1 \mathrm{~g} / \mathrm{dm}^{3}$ ) and then it increased to $49 \%$. For the averaged process wastewater with initial COD $1720 \mathrm{mg} \mathrm{O} / \mathrm{dm}^{3}$, the doses of acetic acid added were $0.8,2.1,4.2$, 6.2 and $8.3 \mathrm{~cm}^{3} / \mathrm{dm}^{3}$. The amounts of $\mathrm{FeSO}_{4} \cdot 7 \mathrm{H}_{2} \mathrm{O}$ and hydrogen peroxide were constant, i.e. $2 \mathrm{~g} / \mathrm{dm}^{3}$ and $40 \mathrm{~cm}^{3} / \mathrm{dm}^{3}$, respectively. The values of COD in the wastewater prior to and after the Fenton process are given in Fig. 4.

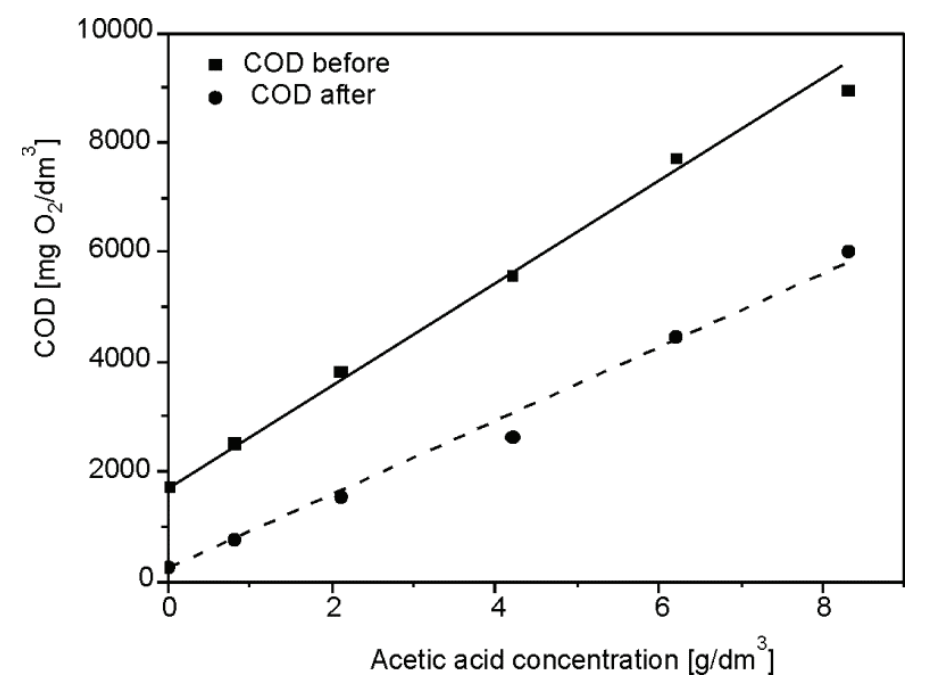

Fig. 4. Effect of acetic acid on COD in averaged wastewater before and after the Fenton process.

Amounts of $\mathrm{FeSO}_{4} \cdot 7 \mathrm{H}_{2} \mathrm{O}-2.0 \mathrm{~g} / \mathrm{dm}^{3}$, and $\mathrm{H}_{2} \mathrm{O}_{2}-20 \mathrm{~cm}^{3} / \mathrm{dm}^{3}$

In a general averaged process wastewater, like in the washing wastewater, the value of COD before and after the Fenton process changed linearly upon increasing concentration of the acetic acid. Also in this case, the slopes of both straight lines were different which caused that the percentage of COD reduction decreased from $68.6 \%$ to $32.9 \%$ upon increasing $\mathrm{CH}_{3} \mathrm{COOH}$ concentration from 0.8 to $8.3 \mathrm{~g} / \mathrm{dm}^{3}$. In the experimental conditions, the maximum COD reduction in the averaged wastewater was $84.3 \%$.

The last tested sample was a concentrate coming from the nanofiltration of wastewater from dyeing of cotton knitwear with initial COD $4930 \mathrm{mg} \mathrm{O} / \mathrm{dm}^{3}$. In this case, $0.4,1,2$ and $4 \mathrm{~cm}^{3} / \mathrm{dm}^{3}$ of acetic acid was added. The amounts of $\mathrm{FeSO}_{4} \cdot 7 \mathrm{H}_{2} \mathrm{O}$ and 
hydrogen peroxide were constant and equal to $4 \mathrm{~g} / \mathrm{dm}^{3}$ and $80 \mathrm{~cm}^{3} / \mathrm{dm}^{3}$, respectively. Figure 5 shows the values of COD in the wastewater before and after the Fenton process.

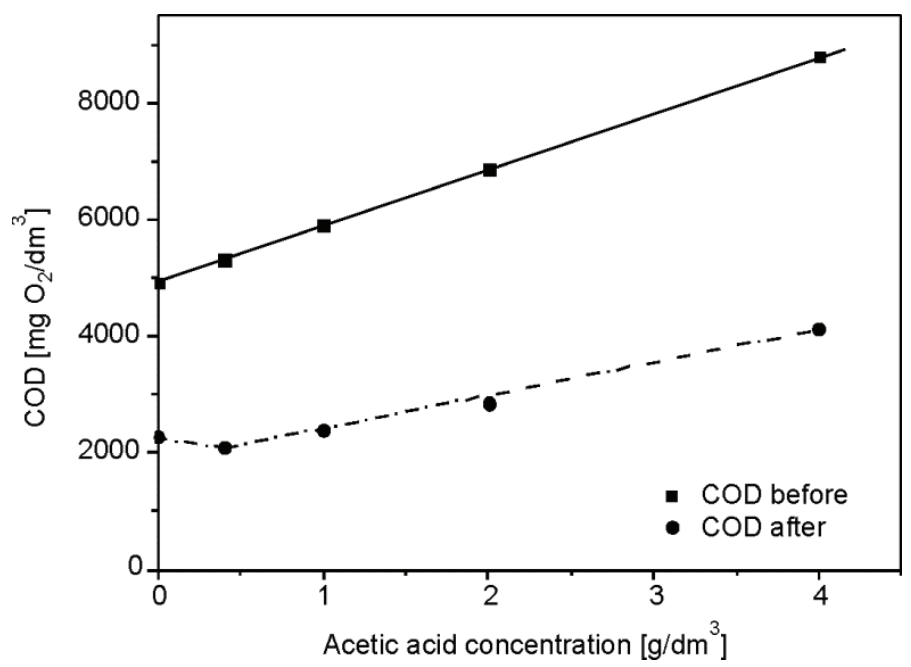

Fig. 5. Effect of acetic acid on COD in the concentrate before and after the Fenton process.

Amounts of $\mathrm{FeSO}_{4} \cdot 7 \mathrm{H}_{2} \mathrm{O}-4.0 \mathrm{~g} / \mathrm{dm}^{3}$, and $\mathrm{H}_{2} \mathrm{O}_{2}-80 \mathrm{~cm}^{3} / \mathrm{dm}^{3}$

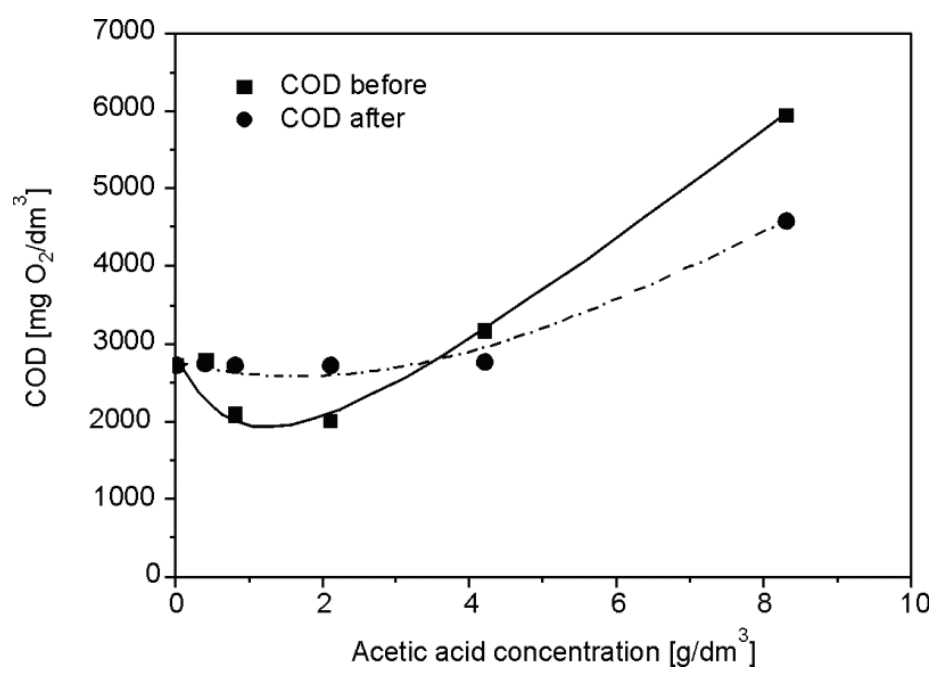

Fig. 6. Calculated and experimental COD values for a dyeing wastewater-acetic acid mixture vs. acetic acid concentration

Similarly as in the case of the washing and averaged wastewater, in the concentrate there is practically a rectilinear dependence of the COD value after the Fenton 
process on the acetic acid concentration. Addition of acetic acid initially improved slightly the COD reduction which was $60.3 \%$ (for $0.4 \mathrm{~g} / \mathrm{dm}^{3}$ ) and $58.4 \%$ (for $2 \mathrm{~g} / \mathrm{dm}^{3}$ ). For the solution with the acetic acid concentration of $4 \mathrm{~g} / \mathrm{dm}^{3}$, the reduction was $53 \%$, similarly as for the initial wastewater.

The calculation of COD reduction for individual mixtures of the wastewater with acetic acid was based on the COD reduction for single components, i.e. the wastewater and acetic acid solutions at a given concentration. These results referring separately to acetic acid and to textile wastewater were published in our previous studies. The calculated values of COD were compared to those obtained experimentally in the oxidation of individual wastewater-acetic acid mixtures. Figures $6-10$ show these dependences for particular types of wastewater.

As follows from Fig. 6, at acetic acid concentrations reaching $3.5 \mathrm{~g} / \mathrm{dm}^{3}$, pollutants present in the wastewater and estimated by the COD were oxidized to a lesser extent than it would follow from the principle of additivity. At the acetic acid concentrations exceeding $3.5 \mathrm{~g} / \mathrm{dm}^{3}$ pollutants were better oxidized.

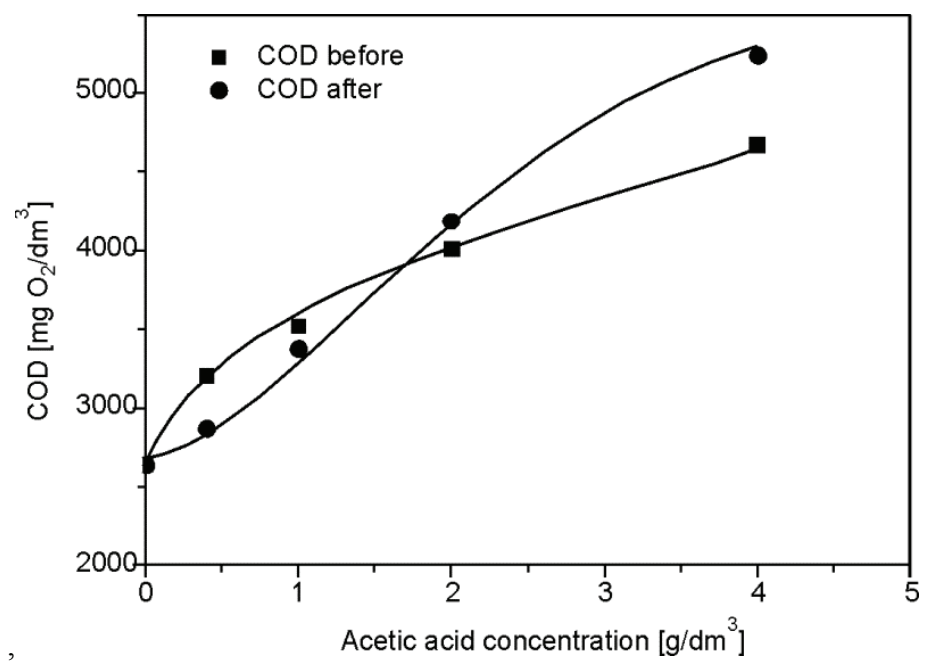

Fig. 7. Calculated and experimental COD values for the concentrate -acetic acid mixture vs. acetic acid concentration

Figure 7 shows results for the concentrate. In this case, a dependence opposite to that for dyeing wastewater was obtained. At the acetic acid concentration amounting to $3.5 \mathrm{~g} / \mathrm{dm}^{3}$, pollutants in the wastewater and measured by the COD value were oxidized better than it would follow from the principle of additivity. At the acid concentrations above $3.5 \mathrm{~g} / \mathrm{dm}^{3}$, the oxidation of pollutants was worse. Results for washing wastewater-1 are shown in Fig. 8. At acetic acid concentrations up to $4.75 \mathrm{~g} / \mathrm{dm}^{3}$, pollutants contained in the wastewater were oxidized worse, while at higher concentrations - better. 
As shown in Figure 9, for washing wastewater-2 actually in the whole range of acetic acid concentrations an increase in the oxidation efficiency was observed, while for the general averaged process wastewater, the efficiency of oxidation was actually deteriorated in the entire range of acetic acid concentrations (Fig. 10).

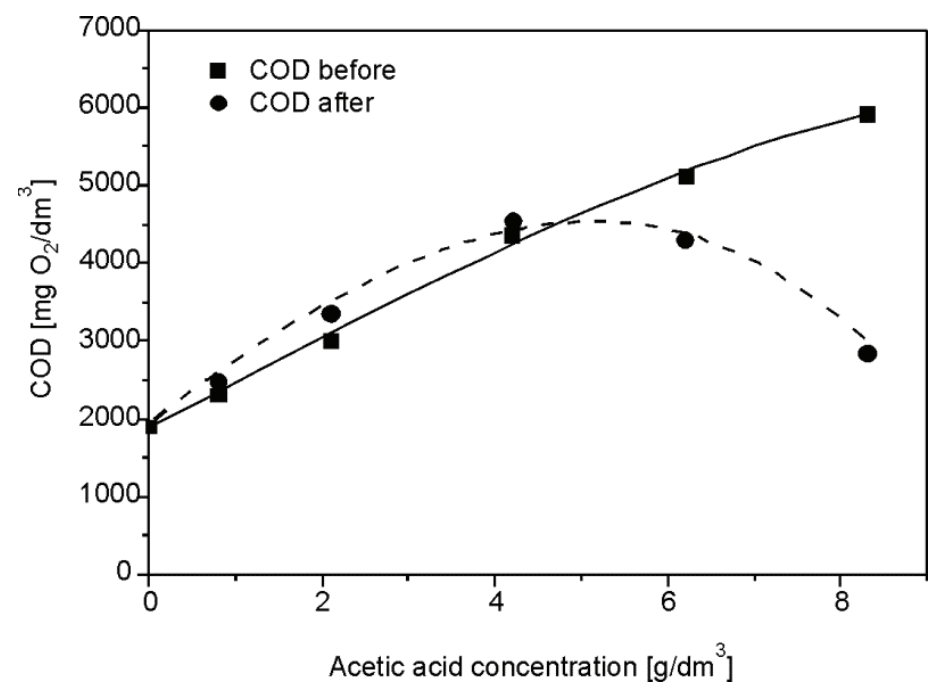

Fig. 8. Calculated and experimental COD values for washing wastewater-1-acetic acid mixture vs. acetic acid concentration

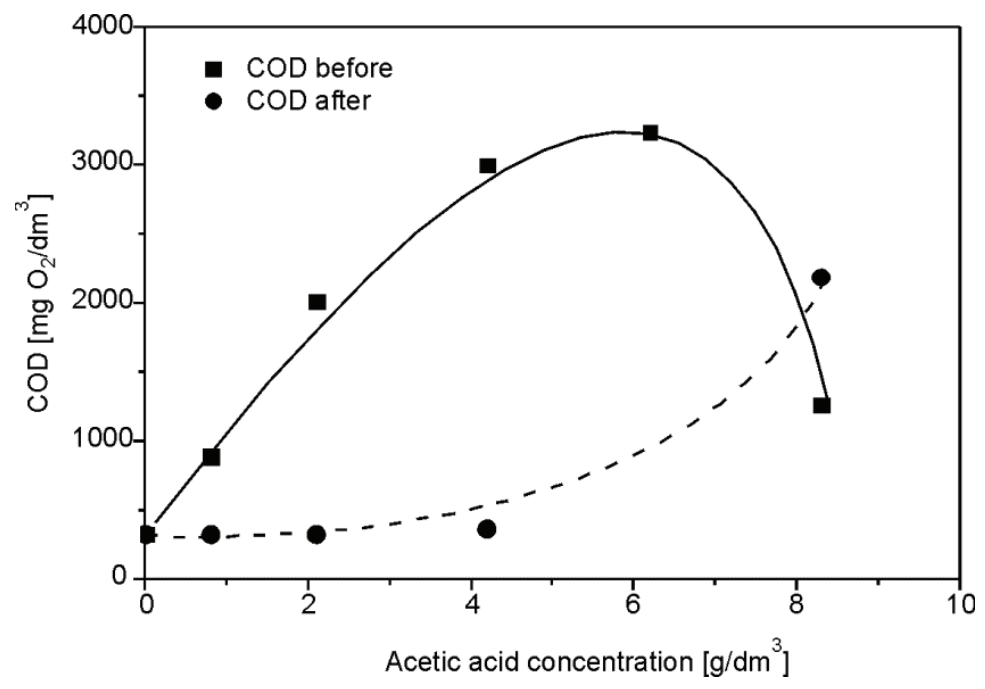

Fig. 9. Calculated and experimental values of COD for washing wastewater-2-acetic acid mixture vs. acetic acid concentration 


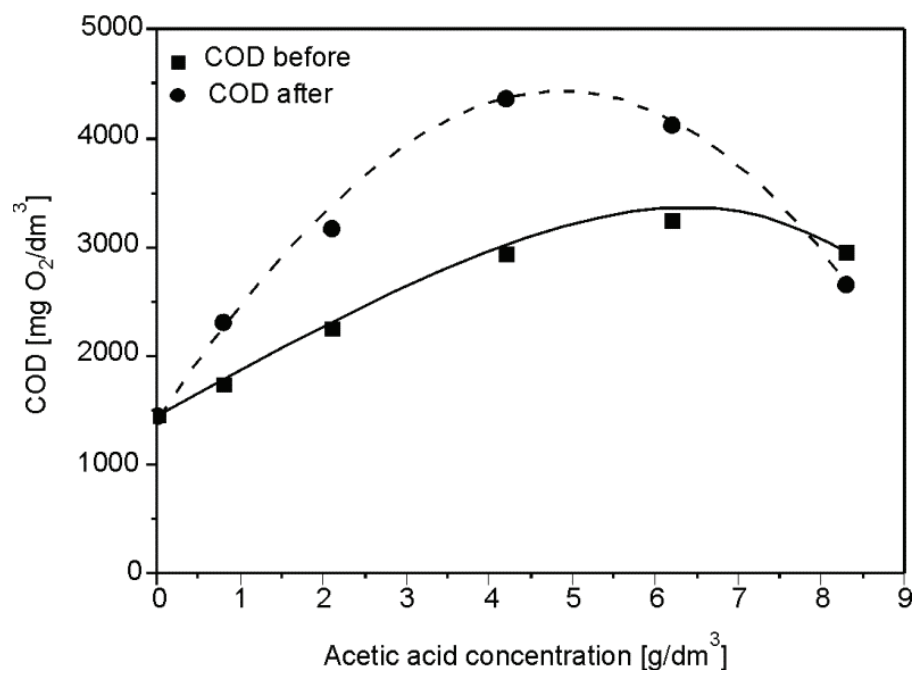

Fig. 10. Calculated and experimental values of COD for general averaged wastewater-acetic acid mixture vs. acetic acid concentration

The experiments show that the presence of acetic acid in the textile wastewater has a significant effect on the mechanism of oxidation and on the decomposition of pollutants present in the wastewater. Already an addition of several g/ $\mathrm{dm}^{3} \mathrm{CH}_{3} \mathrm{COOH}$ to the textile wastewater affects COD, increasing it evidently. Acetic acid deteriorates appreciably conditions of wastewater treatment which affects the process efficiency. Although absolute values of COD reduction usually increase, the reduction of pollution given in percent of the initial wastewater decreases clearly even at small amounts of the acid ranging from 0.4 to $0.8 \mathrm{~g} / \mathrm{dm}^{3}$.

Figures 1-5 show the dependences of COD reduction on the amount of acetic acid added to the wastewater. Their character depends on the type of tested wastewater and pollutants it contains. Most frequently a linear relation was obtained as it was the case in washing wastewater-1, general averaged process wastewater and concentrate. Parabolic relations were obtained for washing-2 and dyeing wastewater.

Figures 6-10 show that experimental results of COD reduction are usually worse which indicates that acetic acid inhibits decomposition of pollutants in the textile wastewater. Even when acetic acid enhances the absolute reduction of pollutants in the wastewater, the value of COD in the treated wastewater is high compared to that in initial wastewater which is caused by the presence of not decomposed acid.

Organic low-molecular compounds are the main intermediate and final products in the processes of oxidation of pollutants present in different types of wastewater. Additionally, acetic acid often occurs in the textile wastewater as one of its main components. It can be concluded that acetic acid hampers complete mineralization of the 
treated wastewater. Hence, it is very important to know the effect of this compound on the final efficiency of oxidation, not only for scientific but also technological reasons.

\section{CONCLUSIONS}

Acetic acid present in textile wastewater has a significant influence on pollutant decomposition during the Fenton process. It significantly deteriorates the conditions of wastewater treatment which affects the process efficiency.

Acetic acid has also a negative effect on the decomposition of pollutants, hampering their mineralization.

Results of the treatment depend on the concentration acetic acid and on the initial composition of the wastewater.

\section{REFERENCES}

[1] Papadopoulos A.E., Fatta D., Loizidou M., J. Hazard. Mater., 2007, 146, 558.

[2] Bazar N., Yonar T., Kestioglu K., Chemosphere, 2004, 55, 35.

[3] Kusic H., Bizic A., Koprivanac N., Dyes Pigments, 2007, 74, 380.

[4] Kos L., Michalska K., Perkowski J., Fibres Text. East. Eur., 2010, 18, 105.

[5] Walling C., Goosen A., J. Am. Chem. Soc., 1973, 95, 2987.

[6] Mizuno T., Tsuno H., Yamada H., Takeshima D., Ozone Sci. Eng., 2008, 30, 263.

[7] Sinha A., Chakrabarti S., Chaudhuri B., Bhattacharjee S., Ray P., Roy S.B., Ind. Eng. Chem. Res., 2007, 46, 3101.

[8] Ma J., Ma W., Song W., Chen C., Tang Y., Zhao J., Huang Y., Xu Y., Zang L., Environ. Sci. Technol., 2006, 40, 618.

[9] Centi G., Perathoner S., Torre T., Verduna M.G., Catal. Today, 2000, 55, 61.

[10] Abd El-Raady A.A., NaKajima T., Ozone Sci. Eng., 2006, 28, 53.

[11] Rossetti G.H., Albizzati E.D., Alfamo O.M., Ind. Eng. Chem. Res., 2002, 41, 1436.

[12] Kang S.F., Liao C.H., Chen M.C.Kang S.F., Chemosphere, 2002, 46, 923. 